\title{
Maxillofacial Radiology 191
}

\author{
SADJ June 2021, Vol. 76 No. 5 pX
}

\section{J Walters}

A 9-year-old female presented with a history of a firm painless bony swelling at the left mandible. A pantomograph (Figure 1) revealed a large radiopaque mass in the mandibular body with impaction of the 36 . What are the most distinguishing radiological features and what is your provisional diagnosis?
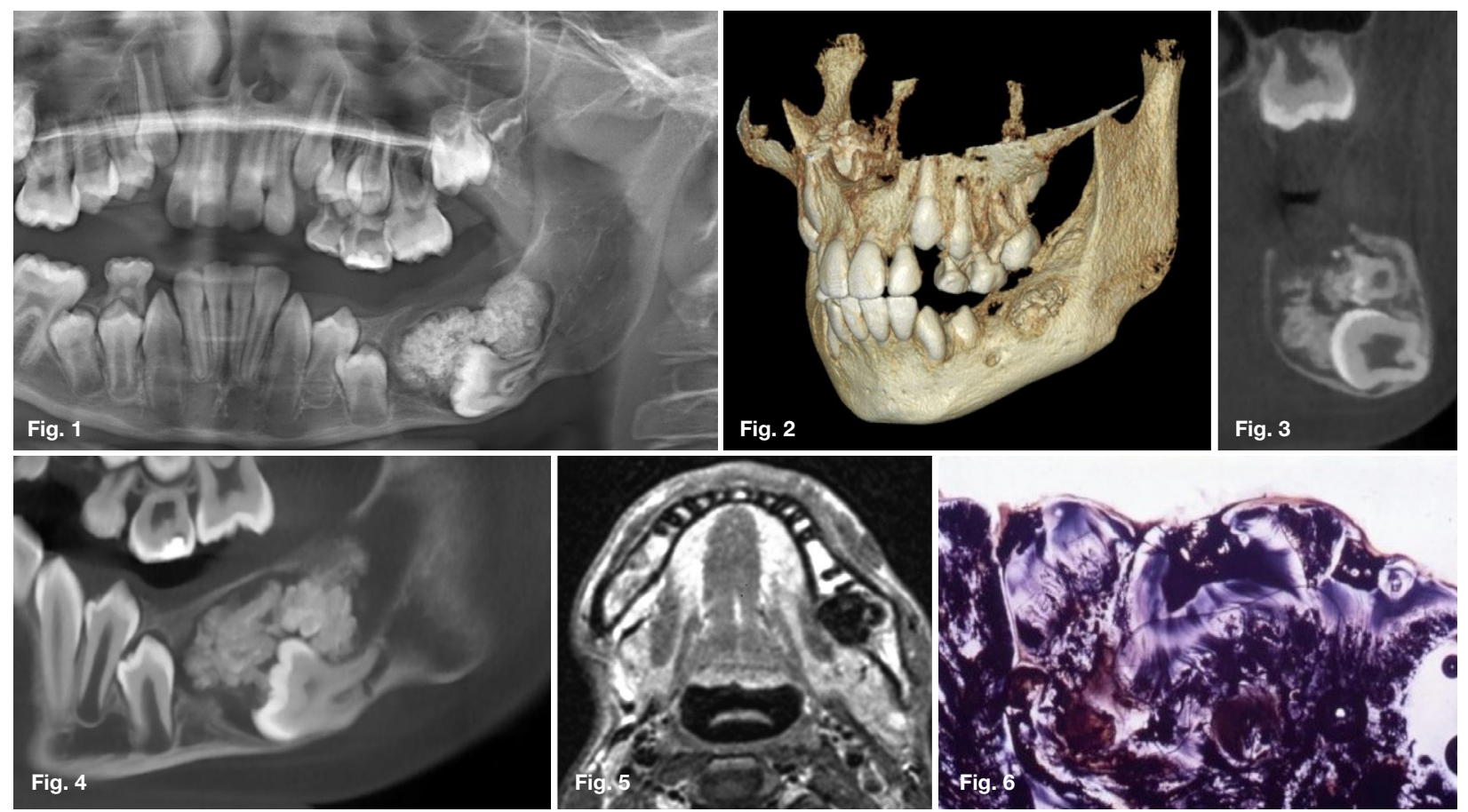

\section{INTERPRETATION}

The lobulated radiopaque lesion appears encapsulated within a cystic-like shell demonstrated as a thin radiolucent corticated rim. 3D rendering (Figure 2) shows an expansile lesion in the left mandibular body. Coronal (Figure 3) and sagittal oblique (Figure 4) CBCT slices depict the lesion as a predominantly tooth-like intermediate-density with high densities throughout similarly to dentine and enamel. Multiple pulp-like structures can be observed as low densities superior to the impacted molar. Buccal lingual expansion, transposition of the inferior alveolar nerve canal, thinning of cortices, irregularity of inferior mandibular border, displacement of the 35 , and dilaceration of the 36 mesial root was noted. The T1-weighted gadolinium-enhanced axial MRI (Figure 5) demonstrates another patient with a similar lesion in the left mandible appearing as a well-circumscribed low signal intensity surrounded with a soft tissue capsule and septation. A photomicrograph (Figure 6) of a histological slide shows haphazardly arranged dental hard and soft tissue.

Jaco Walters: BChD PDD (MFR) PGD (OS) MSc (MFR), Department of Oral and Maxillofacial Radiology, Faculty of Dentistry, University of the Western Cape, Tygerberg Oral Health Centre, Francie Van Zijl

Drive, Cape Town 7505, South Africa.

ORCID Number: 0000-0002-0593-6890

Email: jawalters@uwc.ac.za
The complex odontoma is defined as a malformation with all dental tissues being represented where dental hard tissue is well developed but occur in a disorderly pattern. Differentiation between odontoma variants may be considered subjective. As it is based on the appearance of the internal contents' arrangement. The complex often has an ovoid appearance when compared to the compound which is irregular in shape. The content of these lesions appear greater in density compared to bone. With the complex variant demonstrating characteristically haphazard arrangement and the compound odontoma appearing more organized consisting of multiple denticles.

Generally asymptomatic, slow-growing, and expansile. The mean age of diagnosis is at 19-years-old. A predilection for the posterior mandible has been demonstrated. The association of multiple odontomas in Gardner's syndrome has been widely reported. Even though the complex odontoma is considered self-limiting. When inadequately treated in its initial predominant soft tissue stage, recurrence may occur.

\section{References}

1. Langlais RP, Langland OE, Nortjé CJ. Diagnostic Imaging of the Jaws. Williams \& Wilkins. 1995.

2. Reichart P, Philipsen HP. Odontogenic Tumors and Allied Lesions. Quintessence. 2004. 